\title{
ALERGINIS RINITAS: DIAGNOSTIKA IR GYDYMAS
}

\author{
Rasa Saulyte் ${ }^{1}$, Monika Jasinskaité1, Vassim Valid Ajaj ${ }^{2}$ \\ ${ }^{1}$ Lietuvos sveikatos mokslu universiteto Medicinos akademijos Medicinos fakultetas, \\ ${ }^{2}$ Visagino ligonine, Konsultaciju skyrius
}

Raktažodžiai: alerginis rinitas, intranazaliniai kortikosteroidai, imunoterapija

\begin{abstract}
Santrauka
Tikslas - atlikti mokslinių šaltinių, nagrinèjančių alerginio rinito klinikinę reikšmę, sisteminę analizę, apibendrinti diagnostiką ir gydymą. Duomenys rinkti iš kompiuterinių bibliografinių medicinos duomenų bazių PubMed, Science Direct ir Medscape. Apžvalgai naudoti 2015-2020 metais spausdinti straipsniai anglų kalba, atitinkantys tyrimo temą. Tyrimo rezultatai parodè, kad alerginis rinitas (AR) yra nosies gleivinès uždegimas, kurį sukelia alergenų ir imunoglobulinų E (IgE) poveikis. Kliniškai jam būdingi keturi pagrindiniai simptomai - rinorejja, čiaudulys, nosies niežejimas ir nosies užgulimas. AR gali būti siejamas su gretutinemis ligomis, tokiomis kaip astma, atopinis dermatitas ir nosies polipai. AR diagnozè ir gydymas turètų atitikti naujausias gaires. AR gydymas turètų apimti alergenų vengimą (kai tik įmanoma), farmakoterapiją ir alergenų imunoterapiją. Efektyviausias alerginio rinito gydymas yra intranazaliniais kortikosteroidais.
\end{abstract}

\section{Ivadas}

Alerginis rinitas, dar vadinamas alergine sloga, yra alergenų ir IgE sukeltas nosies gleivinès uždegimas, kurio pagrindiniai simptomai yra rinorejja (vandeningos išskyros), čiaudulys, nosies niežėjimas bei užburkimas (obstrukcija). Iš visų atopinių susirgimų, AR pasireiškia dažniausiai [1]. AR Europoje serga 20-30 proc. suaugusiujjų ir šiek tiek daugiau vaiku. Varginantys ligos simptomai blogina nakties miego kokybę, mažina darbingumą, sukelia mieguistumą dienos metu. Tai smarkiai blogina gyvenimo kokybę [2]. Pastaraisiais metais medikamentinis AR gydymas smarkiai nekito. Gydymas yra simptominis ir taikomas individualiai, atsižvelgiant ị simptomų tipą ir sunkumą. I rinką pateko nedaug naujų produktų, o pagrindinis gydymas vis dar yra pagrịstas intranazaliai vartojamais antihistamininiais vaistais bei gliukokortikoidais [3].
Darbo tikslas - atlikti 2015-2020 metais išspausdintų mokslinių šaltinių, nagrinėjančių AR klinikinę reikšmę, sisteminę analizę, apibendrinti diagnostiką ir gydymą.

\section{Tyrimo medžiaga ir metodai}

Atlikta mokslinès literatūros apžvalga. Duomenys rinkti iš kompiuterinių bibliografinių medicininių duomenų bazių PubMed, Science Direct ir Medscape. Paieška buvo vykdoma naudojant reikšminius žodžius: allergic rhinitis, diagnosis of allergic rhinitis, treatment.

Apžvalgai naudoti 2015-2020 metais spausdinti straipsniai anglų kalba, atitinkantys tyrimo temą.

\section{Tyrimo rezultatai}

Alerginio rinito rizikos veiksniai. Vienas svarbiausių AR išsivystymo rizikos veiksnių yra šeiminè atopinė anamnezè. Kitas veiksnys - padidèjęs serumo IgE (>100 IU/mL) iki 6 metų vaikams. Aukštesnè socioekonominè padètis bei teigiamas alerginis odos dūrio testas taip pat siejami su didesne AR rizika. Dažnesni infekciniai susirgimai ankstyvoje vaikystejje, naminių gyvūnų auginimas bei tabako dūmų įtaka atopijos ir AR vystymuisi vis dar neaiški [4]. Nustatyta, kad žmonèms, gimusiems žiedadulkių sezono metu, padidèja atopinių ligų rizika. Alerginès slogos pasireiškimui ịtakos turi vyriška lytis bei dažnas antibiotikų vartojimas ankstyvoje vaikystejje [5].

Patogenezė. Antigenai, sensibilizuotų asmenų ịkvèpti per nosies gleivinę, prasiskverbia per nosies gleivinès epitelio ląsteles ir prisijungia prie IgE antikūnų ant putliujų ląstelių, pasiskirsčiusių nosies gleivinejje. Reaguodami į antigenoantikūno reakciją, iš putliujų ląstelių išsiskiria cheminiai mediatoriai, tokie kaip histaminas ir peptidiniai leukotrienai. Tai dirgina jutimines nervų galūnes ir nosies gleivinès kraujagysles. Tokiu būdu sukeliamas čiaudulys, rinorejja ir nosies gleivinès patinimas. Tai ankstyvosios fazès reakcija [6]. Ivairios uždegiminès ląstelès, tokios kaip aktyvuoti eozinofilai, infiltruojasi į nosies gleivinę, veikiamą antigenų. Išsiskiria didžiulis citokinų ir chemokinų kiekis [7]. Mediatoriai leukotrienai, kuriuos gamina uždegiminès ląstelès, sukelia 
nosies gleivinès patinimą. Tai vèlyvosios fazės reakcija, pastebima praejus 6-10 valandų nuo antigeno poveikio [8].

Simptomai. Pagrindiniai AR simptomai yra rinoreja, nosies obstrukcija ir užsikimšimas, nosies niežèjimas bei pasikartojantis čiaudulys. Lydintys simptomai yra alerginis konjunktyvitas, kuriam būdinga niežtinčios, paraudusios, ašarojančios ir patinusios akys. Pacientai dažnai suvokia šiuos simptomus kaip nereikšmingus, tačiau tyrimai rodo, kad ši simptomatika turi neigiamą poveikį žmonių gyvenimui. Irodyta, kad tiek AR, tiek alerginis konjunktyvitas riboja kasdienę veiklą ir jos produktyvumą. Pacientai dažnai sunkiai užmiega, prastèja miego kokybè, visa tai neigiamai veikia fizinę ir protinę veiklą, o taip pat ir gyvenimo kokybę [9].

Diagnostika. Diagnostiką apima anamnezè, apžiūra, priekine rinoskopija ir nosies endoskopija (esant nuolatiniam AR) bei odos alerginiai mėginiai ar alergenui specifinių IgE nustatymas serume [10]. Apžiūros metu matomi AR būdingi požymiai: skersinè nosies raukšlè, alergijos ratilai ir alergijos saliutas [11]. Priekinè rinoskopija ir nosies endoskopija padeda AR diferencijuoti nuo kitų priežasčių, tokių kaip polipai ar anatominiai pakitimai [12]. Odos alerginiai méginiai ir alergenui specifinių IgE nustatymas serume patvirtina atopiją bei nustato veiksnị, sukeliantị alerginę reakciją [13]. Dažniausiai naudojamas in vivo IgE testas yra odos dūrio méginys, atliekamas su alergeno ekstraktais ir padedantis nustatyti greitojo tipo alergines reakcijas [14]. In vitro $\operatorname{IgE}$ tyrimai, ypač pagrịsti alergenų komponentais, suteikia galimybę atskirti tikrą įsijautrinimą ir kryžminį reaktyvumą [15]. AR diagnozé nustatoma remiantis trimis simptomais (čiaudulys ir nosies niežulys, vandeninga rinorejja ir nosies obstrukcija) kartu su teigiamu nosies eozinofilų tyrimu ir nustatytais priežastiniais alergenais, remiantis odos dūrio mèginiu arba serume nustatytais alergenams būdingais $\operatorname{IgE}$ antikūnų matavimais [8].

Gydymas. Egzistuoja daugybė rinito fenotipų ir endotipų. AR tradiciškai klasifikuojamas ị sezoninị alerginį rinitą (SAR), nuolatinį alerginị rinitą (NAR) ir mišrų rinitą (kombinuotą alerginị ir nealergini fenotipa). Nepaisant klasifikavimo sistemos, pagrindinis gydymo tikslas yra pasiekti ir palaikyti simptomų kontrolę [16].

Sezoninis AR trunka mažiau nei 4 dienas per savaitę arba trumpiau kaip 4 savaites. Gydymas priklauso nuo simptomų sunkumo [17]. Esant lengvai formai, peroraliai skiriami pirmosios kartos antihistaminiai vaistai, blokuojantys histamino H1 receptorius [18]. Nuolatiniams vidutinio sunkumo ar sunkiems sezoninio rinokonjunktyvito simptomams gydyti skiriamas intranazalinis kortikosteroidas arba intranazalinis antihistamininis preparatas. Nors buvo įrodyta, kad intranazalinis kortikosteroidas sumažina SAR simptomus, tačiau norint geriau kontroliuoti akių alergijos simptomus, reko- menduojama skirti pirmosios kartos antihistaminini preparatą, turintị stabilizuojančių putliujų ląstelių savybių (pvz., kromoliną, pemirolastą, nedokromilą) [19]. Jei intranazalinis gydymas kortikosteroidu neefektyvus, tikslingiausia skirti kombinuotą gydymą, pridedant intranazalinị antihistamininị preparatą [20]. Irodyta, kad flutikazono proprionato ir azelastino hidrochlorido derinys yra veiksmingesnis mažinti SAR simptomus, lyginant su monoterapija [21,22]. Nors kai kurie gydytojai vis dar dažnai skiria ilgo veikimo kortikosteroidų injekcijas ị raumenį, SAR gydymas šiais preparatais nerekomenduojamas dèl sisteminio nepageidaujamo poveikio, tokio kaip antinksčių nepakankamumas ar audinių atrofija injekcijos vietoje [23]. Pacientams, besiskundžiantiems nosies užgulimu ar čiauduliu, nekontroliuojamu antihistaminiais preparatais bei kortikosteroidais, gali būti skiriami geriamieji dekongestantai, tokie kaip pseudoefedrinas [16]. Nustatyta, jog antileukotrienų ir antihistamininių vaistų derinys sukèlè sinergini poveiki, gydant SAR. Ši kombinacija efektyviai veikia visus nosies simptomus ir yra gerai toleruojama vyresnio amžiaus pacientų [3].

Nuolatinis AR trunka daugiau nei 4 dienas per savaitę arba ilgiau nei 4 savaites. Sergant NAR, svarbu nustatyti konkrečius alergenus, kuriems ịsijautrinama ir tinkamai prižiūrèti patalpų orą [24]. Nuolatinio AR klinika ne visada gali būti tokia ryški, kaip sergant sezoniniu AR, todèl medikamentinis gydymas gali skirtis. Dvigubai koduotas placebu kontroliuojamas tyrimas parode, jog antrosios kartos geriamieji antihistamininiai preparatai pacientams, sergantiems NAR, buvo efektyvesni [25].Taigi, cetirizinas bei levocetirizinas yra indikuotini NAR gydymui bei gerai toleruojami [26]. Pacientams, kuriems pasireiškia lengva NAR forma, gydymas pradedamas antros kartos antihistamininiais preparatais, o vèliau, jei simptomatika išlieka, rekomenduojama papildomai skirti intranazalini kortikosteroidą arba intranazalini antihistaminini preparatą [27,28].

Specifine imunoterapija (SIT) yra saugi, efektyvi ir ilgalaikè klinikinius alergijos simptomus mažinanti arba panaikinanti gydymo priemonè, padedanti apsaugoti organizmą nuo naujo įsijautrinimo ir astmos išsivystymo [29]. Imunoterapija turètų būti taikoma esant vidutinio sunkumo ar sunkiam nuolatiniam AR, nepasiduodačiam medikamentiniam gydymui, bei pacientams, kurie netoleruoja standartinių gydymo būdų arba nori išvengti ilgalaikio vaistų vartojimo [30]. Specifinè imunoterapija skiriama viena iš dviejų šių vaistų formų: poodinè (leidžiama) arba poliežuvinè (lašinama, purškiama ar kitokia forma vartojama per burną). Tai vienintelis ilgalaikio veiksmingumo AR gydymas [31]. Sergantiems sezonine alergija (sukelta žiedadulkių) imunoterapija taikoma du mėnesius iki žydejjimo sezono pradžios ir keturis mėnesius per patį sezoną. Jeigu gydymas veiksmingas, jis trunka 3-5 


\section{6}

metus [32]. Nutraukus gydymą, imunoterapijos poveikis gali trukti nuo 7 iki 12 metų [30]. Atliktas tyrimas parodè, jog alerginį rinitą ir konjunktyvitą veiksmingiau mažina poodinė imunoterapija, nei poliežuvinè, tačiau poliežuvinè yra saugesnè anafilaksijos rizikos atžvilgiu [33,34]. Omalizumabas - monokloninis antikūnas, kuris selektyviai jungiasi prie IgE sunkiosios grandinès $\mathrm{C} 3$ domeno ir slopina IgE prisijungimą prie receptorių, esančių putliujų ląstelių ir bazofilų paviršiuje. Šis preparatas efektyviai mažina čiauduli ir pagausèjusias nosies išskyras, gerina sergančiujų AR gyvenimo kokybę [35]. Atlikta metaanalizè patvirtino, jog SIT gali užkirsti kelią naujoms sensibilizacijoms bei astmos išsivystymui [36].

\section{Išvados}

1. Alerginio rinito diagnozei patvirtinti svarbūs keturi simptomai - čiaudulys, nosies niežulys, vandeninga rinorèja ir nosies obstrukcija. Auksinis standartas yra odos dūrio méginys - paprasta, greita ir palyginti nebrangi diagnostikos priemone.

2. Pagrindinis gydymas - intranazaliniai kortikosteroidai. Jei šis gydymas neefektyvus, tikslingiausia skirti kombinuotą, pridedant intranazalinị antihistamininị preparatą.

3. Imunoterapija taikoma esant vidutinio sunkumo ar sunkiam nuolatiniam alerginiam rinitui, nepasiduodančiam medikamentiniam gydymui. Poodinè imunoterapija veiksmingesnè, nei poliežuvinè.

\section{Literatūra}

1. KakliHA, Riley TD. Allergic rhinitis. Prim Care 2016;43(3):465-75. https://doi.org/10.1016/j.pop.2016.04.009

2. Hoyte FCL, Nelson HS. Recent advances in allergic rhinitis. F1000 Research 2018;7:F1000 Faculty Rev-1333.

https://doi.org/10.12688/f1000research.15367.1

3. Bozek A. Pharmacological management of allergic rhinitis in the elderly. Drugs Aging 2017;34(1):21-28.

https://doi.org/10.1007/s40266-016-0425-7

4. Meltzer EO. Allergic rhinitis: burden of illness, quality of life, comorbidities, and control. Immunol Allergy Clin North Am 2016;36(2):235-48.

https://doi.org/10.1016/j.iac.2015.12.002

5. Schuler Iv CF, Montejo JM. Allergic rhinitis in children and adolescents. Pediatr Clin North Am 2019;66(5):981-993.

https://doi.org/10.1016/j.pcl.2019.06.004

6. Eifan AO, Durham SR. Pathogenesis of rhinitis. Clin Exp Allergy 2016;46(9):1139-51.

https://doi.org/10.1111/cea.12780

7. Oliveira TB, Persigo ALK, Ferrazza CC, et al. Prevalence of asthma, allergic rhinitis and pollinosis in a city of Brazil: a monitoring study. Allergol Immunopathol (Madr) 2020;48(6):537-544. https://doi.org/10.1016/j.aller.2020.03.010
8. Okubo K, Kurono Y, Ichimura K, et al. Japanese guidelines for allergic rhinitis 2017. Allergol Int 2017;66(2):205-219.

https://doi.org/10.1016/j.alit.2016.11.001

9. Yi L, Shi-Yuan Y, Tang R, et al. Sublingual immunotherapy tablets relieve symptoms in adults with allergic rhinitis. Chinese Medical Journal 2018;131(21):2583-2588.

https://doi.org/10.4103/0366-6999.244108

10. Zhang Y, Wei P, Chen B, et al. Intranasal fluticasone furoate in pediatric allergic rhinitis: randomized controlled study. Pediatr Res 2020 Oct 2.

https://doi.org/10.1038/s41390-020-01180-0

11. Sur DKC, Plesa ML. Chronic nonallergic rhinitis. Am Fam Physician 2018;98(3):171-176.

12. Zhang Y, Wei P, Chen B, et al. Intranasal fluticasone furoate in pediatric allergic rhinitis: randomized controlled study. Pediatr Res 2020 https://doi.org/10.1038/s41390-020-01180-0

13. Wise SK, Lin SY, Toskala E, et al. International consensus statement on allergy and rhinology: allergic rhinitis. Int Forum Allergy Rhinol 2018;8(2):108-352.

https://doi.org/10.1002/alr.22073

14. Eiringhaus K, Renz H, Matricardi P, et al. Componenet-resolved diagnosis in allergic rhinitis and asthma. J Appl Lab Med 2019;3(5):883-898. https://doi.org/10.1373/jalm.2018.026526

15. Onell A, Whiteman A, Nordlund B, et al. Allergy testing in children with persistent asthma: comparison of four diagnostic methods. Allergy 2017;72(4):590-597.

https://doi.org/10.1111/all.13047

16. Bernstein DI, Schwartz G, Bernstein JA. Allergic rhinitis: mechanisms and treatment. Immunol Allergy Clin North Am 2016;36(2):261-78. https://doi.org/10.1016/j.iac.2015.12.004

17. Holmstrom M, Davidsson A, Hellgren J. Allergic rhinitis affects one third of the population. Lakartidningen 2016;113:DSAS.

18. Wallace DV, Dykewicz MS, Oppenheimer J, et al. Pharmacologic treatment of seasonal allergic rhinitis: synopsis of guidance from the 2017 joint task force on parameters. Ann Intern Med 2017;167(12):876-881.

https://doi.org/10.7326/M17-2203

19. Brozek JL, Bousquet J, Agache I, et al. Allergic rhinitis and its impact on asthma (ARIA) guidelines-2016 revision. J Allergy Clin Immunol 2017;140(4):950-958. https://doi.org/10.1016/j.jaci.2017.03.050

20. Kawauchi H, Yanai K, Wang DY, et al. Antihistamines for allergic rhinitis treatment from the viewpoint of nonsedative properties. Int J Mol Sci 2019;20(1):213. https://doi.org/10.3390/ijms20010213

21. Papadopoulos NG, Bernstein JA, Demoly P, et. al. Phenotypes and endotypes of rhinitis and their impact on management: a PRACTALL report. Allergy 2015;70(5):474-94. 
https://doi.org/10.1111/all.12573

22. Bousquet J, Bachert C, Bernstein J, et. al. Advances in pharmacotherapy for the treatment of allergic rhinitis; MP29-02 (a novel formulation of azelastine hydrochloride and fluticasone propionate in an advanced delivery system) fills the gaps. Expert Opin Pharmacother 2015;16(6):913-28.

https://doi.org/10.1517/14656566.2015.1020789

23. Kang HR, Song HJ, Nam JH, et al. Risk factors of asthma exacerbation based on asthma severity: a nationwide population-based observational study in South Korea. BMJ Open 2018;8(3):e020825.

https://doi.org/10.1136/bmjopen-2017-020825

24. Chen QY, Li L, Zhang L, et al. Efficacy of indoor air purification in treating Artemisia pollen allergic rhinitis: study protocol for a randomised controlled trial. BMC Public Health 2018;18(1):841.

https://doi.org/10.1186/s12889-018-5678-0

25. Rapiejko P, Jurkiewicz D, Pietruszewska W, et al. Treatment strategy of allergic rhinitis in the face of modern world threats. Otolaryngol Pol 2018;72(2):1-12.

https://doi.org/10.5604/01.3001.0011.8057

26. Sanchez G, Castro C. Prescription profile and clinical outcomes in patients with allergic rhinitis treated with oral antihistamines or nasal corticosteroids. Int Arch Otorhinolaryngol 2019;23(3):e325-e330.

https://doi.org/10.1055/s-0039-1688968

27. Wheatley LM, Togias A. Clinical practice. Allergic rhinitis. N Engl J Med 2015;372(5):456-63.

https://doi.org/10.1056/NEJMcp1412282

28. Bousquet J, Schunemann HJ, Fonseca J, et al. MACVIAARIA Sentinel NetworK for allergic rhinitis (MASK-rhinitis): the new generation guideline implementation. Allergy 2015;70(11):1372-92.

https://doi.org/10.1111/all.12686

29. James C, Bernstein DI. Allergen immunotherapy: an updated review of safety. Curr Opin Allergy Clin Immunol 2017;17(1):55-59.

https://doi.org/10.1097/ACI.0000000000000335

30. Seidman MD, Gurgel RK, Lin SY, et al. Clinical practice guideline: allergic rhinitis executive summary. Otolaryngol Head Neck Surg 2015;152(2):197-206.

https://doi.org/10.1177/0194599814562166
31. Wahn U, Bachert C, Heinrich J, et al. Real-world benefits of allergen immunotherapy for birch pollen-associated allergic rhinitis and asthma. Allergy 2019;74(3):594-604.

https://doi.org/10.1111/all.13598

32. Shamji MH, Durham SR. Mechanisms of allergen immunotherapy for inhaled allergens and predictive biomarkers. J Allergy Clin Immunol 2017;140(6):1485-1498. https://doi.org/10.1016/j.jaci.2017.10.010

33. Sur DK, Plesa ML. Treatment of allergic rhinitis. Am Fam Physician 2015;92(11):985-92.

34. Kappen JH, Durham SR, Veen HI, et al. Applications and mechanisms of immunotherapy in allergic rhinitis and asthma. Ther Adv Respir Dis 2017;11(1):73-86. https://doi.org/10.1177/1753465816669662

35. Dantzer JA, Wood RA. The use of omalizumab in allergen immunotherapy. Clin Exp Allergy 2018;48(3):232-240. https://doi.org/10.1111/cea.13084

36. Mortuaire G, Michael J, Papon JF, et al. Specific immunotherapy in allergic rhinitis. Eur Ann Otorhinolaryngol Head Neck Dis 2017;134(4):253-258.

https://doi.org/10.1016/j.anorl.2017.06.005

\section{ALLERGIC RHINITIS: DIAGNOSTICS AND TREATMENT \\ R. Saulytė, M. Jasinskaitè, V.V. Ajaj}

Keywords: allergic rhinitis, intranasal corticosteroid, immunotherapy.

Summary

Allergic rhinitis is an inflammatory nasal mucosal condition caused by exposure to allergens that induces inflammation mediated by IgE. Four main signs are clinically characterized: rhinorrhea, sneezing, nasal itching, and nasal congestion. Co-morbid disorders like asthma, atopic dermatitis and nasal polyps may also be associated with it. Guidelines should be taken for the diagnosis and treatment of allergic rhinitis. Allergic rhinitis care should be combined with avoidance of allergens (wherever possible), pharmacotherapy, and immunotherapy of allergens. The most effective modality for treating allergic rhinitis is intranasal corticosteroids.

Correspondence to: rassa.saulyte@gmail.com

Gauta 2020-11-24 